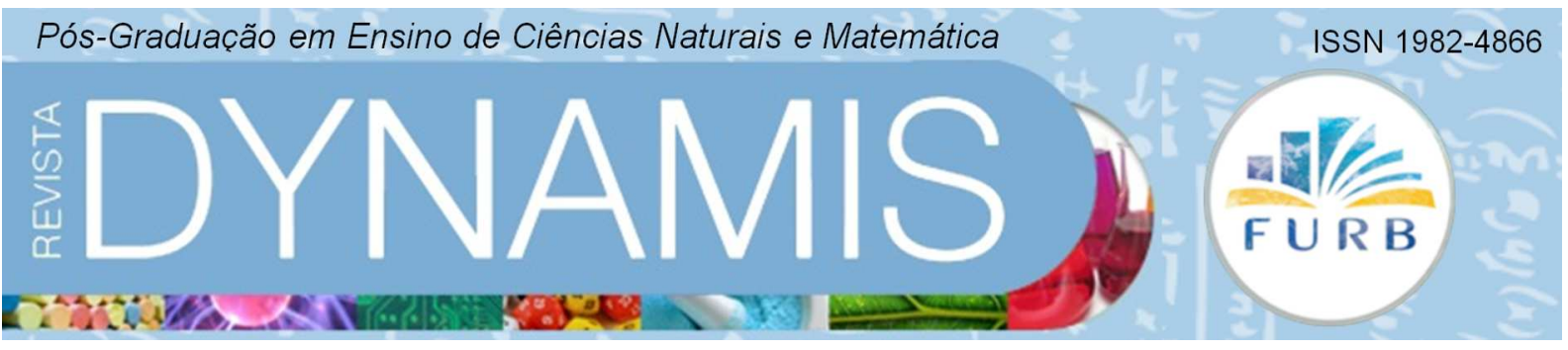

\title{
A APRENDIZAGEM DO CONCEITO DE FUNÇÃO AFIM COM O AUXÍLIO SOFTWARE GEOGEBRA
}

Learning the concept of affine function with software Geogebra

Rudolph dos Santos G.Pereira

Universidade Estadual do Norte do Paraná

rudolphsantos@uenp.edu.br

Willian Damin

Universidade Estadual do Norte do Paraná damimatematica@hotmail.com

Armando Paulo da Silva

Universidade Tecnológica Federal do Paraná armando@hotmail.com 


\title{
Resumo
}

Este artigo apresenta uma atividade cujo objetivo foi verificar a aprendizagem do conceito de função afim. Para tanto, descreve-se a atividade, na qual os alunos em seu desenvolvimento realizaram registros escritos acerca do conceito estudado, o que subsidiou a compreensão qualitativa da aprendizagem deste conceito por meio da análise de conteúdo de Bardin (2009). Ao analisar identificaram-se alguns problemas na aprendizagem do conceito de função afim, porém, o uso do software Geogebra possibilitou a construção do conhecimento pelos alunos, durante o processo de visualização, baseando-se em conceitos previamente aprendidos como também a modificação de outros apropriados de maneira incorreta. Verificou-se que a construção do conhecimento e a verificação da aprendizagem podem ser realizados com o auxílio das TIC, uma vez que estas constituem contexto e podem proporcionar o aprendizado da Matemática além de permitir a análise da prática docente.

Palavras-chave: Tecnologia da informação e comunicação. Função afim. Aprendizagem da Matemática.

\begin{abstract}
This paper presents an activity whose aim was to assess the learning of the concept of affine function. To this end, we describe the activity, in which students in their development conducted written records about the concept study, which supported the qualitative understanding of learning this concept by means of content analysis of Bardin (2009). By analyzing we identified some problems in learning the concept of affine function, however, the use of the software Geogebra enabled the construction of knowledge by students during the visualization process, based on previously learned concepts as well as the modification of other appropriate incorrectly. It is the construction of knowledge and verification of learning can be realized with the help of ITC, since these constitute the context and can provide learning of mathematics and enables the analysis of teaching practice.
\end{abstract}

Keywords: Information of technology and communication. Affine function. Learning of Mathematics. 


\section{INTRODUÇÃO}

As mudanças ocorridas na sociedade têm apresentado fortes influências e características da pós-modernidade. A alteração repentina de atitude, de humor, de desejos, dos costumes das pessoas entre outras tem sido as maiores representações da consequência do mundo pósmoderno. Mas afinal o que se entende por pós-modernismo? Pode-se dizer que é um movimento social que surge como uma forma cultual de dominação e que traz consigo novas maneiras de socialização, de pensar e de agir. "Nesse sentido, o pós-modernismo não engendra apenas uma nova condição existencial, ele produz novos modos de ser e de viver, outros tipos de sujeitos, pessoas pós-modernas [...].” (MOMO; COSTA, 2010, p. 967).

A presença de objetos tecnológicos como telefones celulares, tablets, notebook, entre outros faz com que a escola busque se adaptar aos indivíduos contemporâneos e para tentar cumprir com sua função ela tem a necessidade de aprender a utilizar estes recursos tecnológicos para atrair a atenção dos alunos. A apelação da mídia faz com que cada vez mais as crianças sintam necessidade de adquirir tais objetos e dessa forma a escola deixa de ser o local de aquisição de conhecimentos, e assim, pode-se dizer que a escola usualmente centrada em pedagogias da escrita e da oralidade aos poucos se constitui como mais um lugar em que operam pedagogias visuais, ensinando sobre imagens desejáveis. (MOMO; COSTA, 2010, p. 979).

Acredita-se que toda essa presença dos objetos tecnológicos tem causado desestabilidade na escola e em grande velocidade fazendo com que ela não tenha condições de se adaptar a todas essas características dessa nova sociedade.

[...] cada vez mais crianças, constituídas por novas e variadas práticas culturais, adentram nossas escolas, causando inquietações, desestabilizando e incomodando, porque, de certa forma, já não é mais possível classificá-las e enquadrá-las em uma cartografia. Sem essa garantia de ordem e estabilidade, por longo tempo assegurada pelos enquadramentos pedagógicos modernos, educadores dos tempos pósmodernos estão inseguros, sem rumo, confusos, quase imobilizados. (MOMO; COSTA, 2010, p. 988).

Mesmo com toda a tentativa de inclusão dos recursos tecnológicos na sala aula os professores sentem que há dificuldade de prender a atenção dos alunos, pois não se trata apenas no uso destes recursos e sim de como fazer com que os alunos se interessem pelos conhecimentos escolares.

O que se pode perceber é que a escola tem sofrido perturbações e mesmo com toda iniciativa dos profissionais da educação tem sido quase que impossível fazer com que os alunos tenham interesse em aprender conteúdos disciplinares e dessa forma construam seu próprio conhecimento. Pode-se se dizer que a escola foi invadida por

Seres estranhos, ameaçadores e incompreendidos nos olham nos pátios, corredores e salas de aula. A infância como fase da inocência, da dependência, da insegurança e da ignorância dos segredos do mundo e da vida parece que está desaparecendo rapidamente. No lugar dela instalam-se as infâncias dos tempos pós-modernos, insondáveis, múltiplas, instáveis, paradoxais, selvagens, incontroláveis, enigmáticas. (MOMO; COSTA, 2010, p. 988-989). 
É inegável que o espaço escolar necessita de mudanças e que estas exigem além de políticas públicas, capacitação de professores na formação inicial e continuada para utilização dos recursos tecnológicos bem como a aquisição de equipamentos de tecnologia. Dessa forma, faz-se necessário adequar a sala de aula à realidade dos alunos. É importante que a escola se torne um ambiente atrativo para o ensino de conteúdos disciplinares e a construção de conhecimento, e não somente um local para seus alunos exibirem seus objetos tecnológicos.

\section{O USO DO COMPUTADOR}

A sociedade necessita de indivíduos criativos e com a capacidade para criticar de modo construtivo, pensar, aprender sobre aprender, trabalhar em grupo e conhecer seus próprios potenciais. Isso requer um indivíduo que está atento às mudanças que acontecem em nossa realidade e que tenha a capacidade de constantemente melhorar e reorganizar suas ideias e ações.

Tal necessidade implica na transformação das escolas de hoje. Essa transformação é muito mais profunda do que simplesmente instalar o computador como um novo recurso educacional, pois aprender um determinado assunto deve ser o produto de um processo de construção de conhecimento realizado pelo aprendiz e por intermédio do desenvolvimento de projetos que usam o computador como uma fonte de informação ou recurso para resolver problemas significativos para o aprendiz (VALENTE, 1999).

O computador pode ser um importante recurso no processo de construção de conhecimento pelos alunos. Ao questionarmos "por que usar computadores na educação?", a resposta mais provável é o fato de estarmos interessados em explorar as características dos computadores que contribuem para o processo de conceituação ou construção do conhecimento. Ele pode refletir sobre os resultados de suas ações e ideias, e esta reflexão é o mecanismo pelo qual o aprendiz se torna consciente de seu conhecimento e, assim, pode transformar seus esquemas mentais em operações e noções mais complexas. A grande maioria dos educadores acredita que o computador motiva o aluno, que é a ferramenta da atualidade ou que facilita o aprendizado. No entanto, os diferentes usos do computador na sala de aula levaram à conclusão de que os usos que são mais semelhantes à práticas pedagógicas tradicionais são os menos efetivos para promover a compreensão do que o aprendiz faz (VALENTE, 1999).

Assim, o uso do computador em sala de aula tem modificado a ideia de ser um simples instrumento no processo pedagógico tornando-se um importante auxiliador no processo de ensino e de aprendizagem e na construção de conhecimentos pelo aprendiz, permitindo assim repensar sobre a aprendizagem de conceitos que estão presentes na interação do aprendiz com recurso tecnológico.

Diante desses aspectos, verificou-se a aprendizagem do conceito de função afim, seus parâmetros e o comportamento gráfico, em alunos ingressantes do curso de licenciatura em Matemática por meio da utilização do software Geogebra.

\section{PROCEDIMENTOS METODOLÓGICOS}


Este trabalho foi realizado com quatorze acadêmicos do primeiro ano de um curso de licenciatura em Matemática de uma Instituição de Ensino Superior, pública, do interior do Paraná, na disciplina de Função. Objetivou-se, por meio de uma atividade, verificar a aprendizagem do conceito de função afim, seus parâmetros e o comportamento gráfico por meio da utilização do software Geogebra. Pois, acredita-se que:

\begin{abstract}
O oposto à matemática pronta é a matemática em status nascente. Isto é o que Sócrates ensinou. Hoje, desejamos que isso seja um começo real ao invés de ser estilizado; o educando deve, por ele mesmo, reinventar matemáticas... O processo de aprendizagem tem que incluir fases de invenções dirigidas, isto é, de invenções não no sentido objetivo, mas no senso subjetivo, visto da perspectiva do estudante. (FREUDENTHAL, 1973 apud STEINBRING, 2005, p.15).
\end{abstract}

Para a realização da atividade, dividiram-se os alunos da turma em duplas, na qual se buscou compreender de que forma os acadêmicos entendem o uso de recurso tecnológico na construção do conceito de função. Assim, inicialmente, foi solicitado que fizessem a definição da função afim e o comportamento gráfico da mesma em relação aos seus parâmetros bem como o registro da contribuição do uso do software Geogebra. Para isto, a atividade foi divida em seis momentos que buscaram levar os acadêmicos a refletirem sobre o uso de recursos tecnológicos na construção do conhecimento.

A atividade é detalhada a seguir. No primeiro momento foi solicitado aos acadêmicos que definissem a função afim até mesmo pelo fato de já ter havido um contato com este conceito no Ensino Médio e também na licenciatura em Matemática, na disciplina de Função, no início do período letivo. Após a realização desta etapa da atividade discutiu-se sobre os aspetos definidores da função afim (o conjunto domínio e a função $(x, a x+b)$ ) e os aspectos característicos (dependentes dos parâmetros a e b) que são imagem e comportamento gráfico da função.

Em seguida solicitou-se que realizassem a construção gráfica da função afim e registrassem de modo escrito o comportamento gráfico em relação aos seus parâmetros em cada um dos quatro momentos conforme indicado no Quadro 1:

\title{
Quadro 1 - Situações para análise do comportamento gráfico da função afim
}

\begin{tabular}{|c|c|}
\hline $\begin{array}{c}\text { Mo } \\
\text { mentos }\end{array}$ & Definição dos parâmetros \\
\hline $1^{\mathrm{a}}$ & O valor do parâmetro $a$ ser positivo e o parâmetro $b$ igual a zero. \\
\hline $2^{\mathrm{a}}$ & O valor do parâmetro $a$ ser negativo e o parâmetro $b$ igual a zero. \\
\hline $3^{\mathrm{a}}$ & $\begin{array}{c}\text { O valor do parâmetro } a \text { ser positivo ou negativo e o parâmetro } b \text { diferente } \\
\text { de zero. }\end{array}$ \\
\hline $4^{\mathrm{a}}$ & O valor do parâmetro $a$ ser igual a zero e o parâmetro $b$ diferente de zero. \\
\hline
\end{tabular}

Fonte: da pesquisa 
Posterior a essa atividade, no sexto momento, solicitou-se que os acadêmicos descrevessem de que forma o uso do software Geogebra pode contribuir na aprendizagem do conceito de função afim, pois estes já tiveram o contato com esse conceito, porém, em sua maioria, possivelmente sem o uso de recurso tecnológico. Tal atividade foi elaborada pois acredita-se que

Todo conhecimento matemático, seja ele científico ou escolar, necessita do contexto de referência, e, neste sentido, todo conhecimento é um contexto específico. Sobre esta base, a diferença entre matemática científica e escolar encontra-se nos diferentes tipos de contextos de referências usados nestes diferentes contextos de desenvolvimentos sociais. Uma diferença importante diz respeito ao contexto de referência na matemática escolar, a qual deve ser ajustada para a necessidade da aprendizagem e do desenvolvimento cognitivo dos estudantes. (STEINBRING, 2005, p.13).

As duplas realizaram várias discussões acerca do conceito envolvido na atividade. Durante a realização da atividade buscou-se verificar o conceito de função afim pelo alunos além de apresentar uma atividade que possibilita a construção de conhecimento por meio da utilização do software Geogebra em sala de aula. Assim, ao final da atividade foram recolhidos os registros escritos para análise.

A pesquisa caracterizou-se como qualitativa, pois o pesquisador buscou coletar dados e analisá-los de modo a atingir o objetivo, definidos com a intenção de verificar a aprendizagem do conceito de função afim em acadêmicos do no curso de licenciatura em Matemática. Pois, de acordo com Bogdan e Biklen (1994), a pesquisa qualitativa pode ser entendida como a tentativa de compreensão de significados e características de situações apresentadas por entrevistados ou pesquisados, para se aprofundar nos fenômenos, levando em conta a sua complexidade e particularidades, de maneira a não almejar generalizações e sim a compreensão das singularidades.

Por se tratar de sete duplas, decidiu-se escolher quatro duplas que realizaram a atividade. As duplas foram numeradas de um a sete, sendo escolhidas ao acaso as quatro duplas (D1, D2, D3, D4) que foram analisadas neste trabalho.

Para a análise dos registros produzidos pelos acadêmicos na atividade realizada optouse pela análise de conteúdo, pois é considerado um instrumento de análise interpretativa que possibilita uma compreensão que parte da realidade concreta da situação estudada. Para Moraes (1999, p. 7) a "análise de conteúdo constitui uma metodologia de pesquisa usada para descrever e interpretar o conteúdo de toda classe de documentos e textos" e pode ser considerado um instrumento, "[...] um guia prático para a ação, sempre renovada em função dos problemas cada vez mais diversificados que se propõe a investigar. Pode-se considerá-la como único instrumento, mas marcado por uma grande variedade de formas e adaptável a um campo de aplicação muito vasto, qual seja a comunicação”. (MORAES, 1999, p. 7).

A metodologia de análise de conteúdo constitui um conjunto de procedimentos de análise das comunicações, orais ou escritas, cujo objetivo é encontrar indicadores, qualitativos ou quantitativos, que possibilitem inferir (deduzir de forma lógica) sobre conhecimentos relacionados às mensagens analisadas. Assim, a análise de conteúdo é indicada quando o pesquisador pretende manipular as mensagens para inferir "conhecimentos sobre o emissor da mensagem ou sobre o seu meio". (BARDIN, 2009, p. 34). 
Desse modo, sendo a análise de conteúdo um instrumento que pode ser adaptado a uma variedade de pesquisa, coube ao pesquisador determinar uma maneira de fazer o uso desta metodologia neste trabalho de modo a atingir os objetivos anteriormente definidos.

\section{ESTRUTURA DE ANÁLISE}

Utilizando como base a análise de conteúdo e mediante os aspectos característicos da função afim, definiu-se como categorias a priori os quatro momentos apresentados anteriormente no Quadro 1. Tal escolha de se deu em concordância com o que diz Bardin (1999) a respeito do processo de categorização, pois este "tem como objectivo (da mesma maneira que a análise documental) fornecer, por condensação, uma representação simplificada dos dados brutos" (BARDIN, 1999, p. 112) e também pelo conjunto de "boas características" que as categorias devem possuir:

- $\quad$ a exclusão mútua: esta condição estipula que cada elemento não pode existir em mais de uma divisão. As categorias deveriam ser construídas de tal maneira que um elemento não pudesse ter dois ou vários aspectos susceptíveis de fazerem com que fossem classificados em duas ou mais categorias. [...];

- $\quad$ homogeneidade: o princípio da exclusão mútua depende da homogeneidade das categorias. Um único princípio de classificação deve governar a sua organização. [...];

- $\quad$ a pertinência: uma categoria é considerada pertinente quando está adaptada ao material de análise escolhido, e quando pertence ao quadro teórico definido. [...];

- $\quad$ a objectividade e a fidelidade: estes princípios, tidos como muito importantes no início da história da análise de conteúdo, continuam a ser válidos. As diferentes partes de um mesmo material, ao qual se aplica a mesma grelha categorial, devem ser codificadas da mesma maneira, mesmo quando submetidas a várias análises. [...];

- $\quad$ a produtividade: adicionaremos às condições geralmente invocadas uma qualidade muito pragmática. Um conjunto de categorias é produtivo se fornece resultados férteis: férteis em índices de inferências, em hipóteses novas e em dados exactos. (Bardin, 1999, p. 113-114).

Para a definição das unidades de registro baseou-se nos critérios de correção e avaliação apresentado por Buriasco, Cyrino e Soares (2004) que possibilitam corrigir e registrar a produção discente na resolução de questões abertas. A adoção de tal método se dá tendo em vista que

as respostas dos alunos não devem ser codificadas apenas como certas ou erradas, e sim, separadas inicialmente em três blocos - "responde adequadamente a questão", "responde parcialmente a questão" e "não responde a questão" - e classificadas como - "crédito completo", "crédito parcial" e "nenhum crédito", respectivamente (BURIASCO; CYRINO; SOARES, 2004, p. 5).

As autoras consideram que este método de correção possibilita ao professor verificar a compreensão do aluno em relação ao que foi solicitado na atividade de modo a identificar o que ele já conhece ou está em busca de aprender, pois "se a resposta dada a uma questão está incorreta, necessariamente a produção do aluno deve ser examinada para considerar possíveis créditos parciais". (BURIASCO; CYRINO; SOARES, 2004, p. 6). 
Diante do que foi apresentado definiu-se a estrutura da análise da produção dos alunos neste trabalho como sendo:

- as categorias: os momentos apresentados no Quadro 1;

- as unidades: os critérios definidos por Buriasco, Cyrino e Soares (2004).

Figura 1 - Categorias e unidades de análise
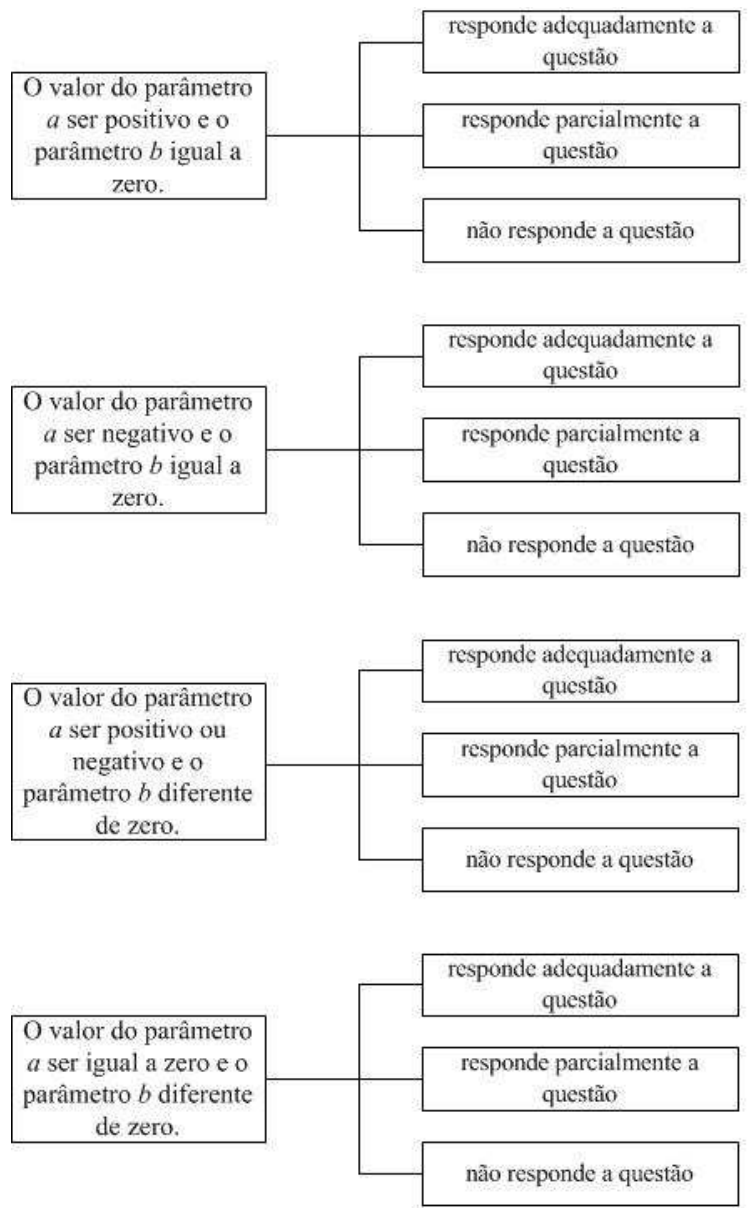

Fonte: da pesquisa

Após escolha da estrutura acima se deu início a análise da produção das quatro duplas selecionadas ao acaso. Os registros apresentados pelas duplas e a avaliação realizada sobre os mesmo com base na análise de conteúdo são apresentados adiante.

\subsection{ANÁLISE DAS ATIVIDADES}

Nos Quadros 2, 3, 4 e 5 apresenta-se, de acordo com a definição da amostra e das categorias de análise, a transcrição dos registros realizados pelas duplas e de modo a comparar as respostas corretas com base na definição e comportamento gráfico da função afim. Em seguida registrou-se um meta texto no qual se buscou compreender a aprendizagem do 
conteúdo contido na atividade por meio dos registros efetuados pelos alunos. Nos Quadros a seguir apresenta-se cada categoria, os registros e os textos criados para a análise das atividades e suas respectivas avaliações (responde adequadamente a questão, responde parcialmente a questão ou não responde a questão).

A primeira análise deu-se da categoria: $\mathrm{O}$ valor do parâmetro a ser positivo e o parâmetro b igual a zero, conforme Quadro 2.

\section{Quadro 2 - Análise da quarta categoria: $O$ valor do parâmetro a ser positivo e o parâmetro $b$ igual $a$ zero}

Categoria: O valor do parâmetro $a$ ser positivo e o parâmetro $b$ igual a zero.

Registro correto: Tem-se uma reta crescente, passando pela origem do plano cartesiano, e a medida que o valor de $a$ aumenta, a abertura angular entre a reta e o eixo das abscissas aumenta, ficando a reta mais próxima do eixo Oy.

\begin{tabular}{|c|l|l|}
\hline Dupla & \multicolumn{1}{|c|}{ Registro do dupla } & Avaliação \\
\hline D1 & $\begin{array}{l}\text { A reta será crescente e passará pelo o ponto de ori- } \\
\text { gem e a reta ficará mais próxima ao eixo de y, quan- } \\
\text { do maior o } a \text { não interceptará nenhum dos eixos. }\end{array}$ & Crédito Parcial (CP) \\
\hline D2 & $\begin{array}{l}\text { A medida que o valor de } a \text { aumenta a reta vai fican- } \\
\text { do mais próxima do eixo y. }\end{array}$ & Crédito Parcial (CP) \\
\hline D3 & $\begin{array}{l}\text { A reta passa pelo ponto origem, devido ao coeficien- } \\
\text { te angular ser positivo, a reta é crescente. }\end{array}$ & Crédito Parcial (CP) \\
\hline D4 & $\begin{array}{l}\text { Quanto maior o parâmetro de } a \text { mais próximo ao } \\
\text { eixo de y fica a reta, sendo crescente. }\end{array}$ & Crédito Parcial (CP) \\
\hline
\end{tabular}

D1: esta dupla faz o registro correto da situação até determinado momento, mas comete um erro na complementação da resposta.

D2: registra apenas a relação do coeficiente angular em relação ao eixo Oy, porém não descrevem as demais características.

D3: pode-se perceber que há certa confusão em relação ao comportamento gráfico da função e seus parâmetros. No registro a dupla justifica que a reta passa na origem do plano cartesiano por seu coeficiente angular ser positivo, o que não está correto.

D4: esta dupla registra que quanto maior o coeficiente angular, mais próxima do eixo Oy a reta estará e será crescente. Porém, deixa de registrar que a mesma passa pela origem do plano cartesiano.

\section{Fonte: da pesquisa}

A interpretação dos dados referente à categoria "O valor do parâmetro $a$ ser positivo e o parâmetro $b$ igual a zero" permite supor que há falta de entendimento do comportamento da 
função em relação ao coeficiente angular e o coeficiente linear. No que diz respeito ao coeficiente angular, a maioria afirma que a reta é crescente em função deste ser positivo e afirma que quanto maior for seu valor, mais próxima do eixo Oy a reta estará. No entanto, esta mesma maioria deixa de registrar que a reta passa pela origem do plano cartesiano e que este fato ocorre em função do valor atribuído ao parâmetro $b$ (coeficiente linear). Dessa forma pode-se afirmar que o fato do coeficiente linear ser nulo, levou os alunos a desconsiderarem as alterações ocorridas no comportamento gráfico da função e que possivelmente a visualização gráfica não se mostrou suficiente para que os alunos realizassem o registro corretamente.

Em seguida analisou-se os registros efetuados pelas duplas em relação a segunda categoria conforme descrito no Quadro 3.

\section{Quadro 3 - Análise da segunda categoria: $O$ valor do parâmetro a ser negativo e o parâmetro $b$ igual a zero}

\begin{tabular}{|c|c|c|}
\hline ano, e & $\begin{array}{l}\text { ategoria: } \mathrm{O} \text { valor do parâmetro } a \text { ser negativo e o parân } \\
\text { egistro correto: Tem-se uma reta decrescente, passand } \\
\text { medida que o valor de } a \text { diminui, a abertura angular } \\
\text { enta, ficando a reta mais próxima do eixo x. }\end{array}$ & $\begin{array}{l}\text { etro } b \text { igual a zero. } \\
\text { pela origem do plano cartesi- } \\
\text { tre a reta e o eixo das abscis- }\end{array}$ \\
\hline Dupla & Registro da dupla & Avaliação \\
\hline D1 & $\begin{array}{l}\text { Reta decrescente, ela ficará mais próxima do eixo y, } \\
\text { a reta também passa pelo ponto de origem. Ela não } \\
\text { interceptará nenhum dos eixos. }\end{array}$ & Crédito Parcial (CP) \\
\hline D2 & $\begin{array}{l}\text { Quanto maior o número negativo de "a", a reta vai } \\
\text { ficando próxima ao eixo, a diferença é que torna-se } \\
\text { uma função decrescente neste caso. }\end{array}$ & Crédito Parcial (CP) \\
\hline D3 & $\begin{array}{l}\text { A reta passa pelo ponto de origem, assim como no } \\
\text { primeiro caso, o que difere as duas é o coeficiente } \\
\text { angular, que neste caso é negativo. Sendo assim a } \\
\text { reta será decrescente. }\end{array}$ & Crédito Parcial (CP) \\
\hline D4 & $\begin{array}{l}\text { Quando os valores de } a \text { são negativos a reta é de- } \\
\text { crescente e quanto menor os parâmetros de } a \text { mais } \\
\text { próximo do eixo de y fica a reta. }\end{array}$ & Crédito Parcial (CP) \\
\hline $\begin{array}{l}\text { D } \\
\text { do plan } \\
\text { xima d }\end{array}$ & $\begin{array}{l}\text { a dupla registra adequadamente que a reta é decresc } \\
\text { cartesiano, porém faz afirmação indevida quando re } \\
\text { eixo Oy e que não interceptará nenhum dos eixos. }\end{array}$ & $\begin{array}{l}\text { nte e que passará pela origem } \\
\text { ta que a reta ficará mais pró- }\end{array}$ \\
\hline $\begin{array}{l}\text { D } \\
\text { da afirı } \\
\text { eixo" e } \\
\text { valor n } \\
\text { angular } \\
\text { mais pr }\end{array}$ & $\begin{array}{l}\text { : o registro realizado por esta dupla tem apenas uma i } \\
\text { ação de que a reta é decrescente. Porém, afirma que } \\
\text { ão identifica de que eixo, e também, registra a segu } \\
\text { zativo de a", o que demonstra que há uma tentativa de } \\
\text { ender ao infinito negativo, ou seja, quanto menor es } \\
\text { xima do eixo Ox. }\end{array}$ & $\begin{array}{l}\text { nformação correta, que se trata } \\
\text { 'a reta ficará mais próxima do } \\
\text { inte sentença "quanto maior o } \\
\text { descrever que se o coeficiente } \\
\text { te coeficiente, a função ficará }\end{array}$ \\
\hline
\end{tabular}


D3: esta dupla faz a comparação com a situação anterior e comenta que a diferença esta no coeficiente angular que agora é negativo e assim a função tem comportamento decrescente. No entanto, não registra a relação do coeficiente angular e a proximidade com o eixo Ox ou Oy, e também não apresenta a relação do coeficiente linear quando a função intercepta a origem do plano cartesiano.

D4: no registro apresentado por esta dupla pode-se verificar que a mesma considera que a reta é decrescente tendo em vista que o valor do coeficiente angular é negativo, porém há um erro no momento em que registra que "quanto menor os parâmetros de $a$ mais próximo do eixo de y fica a reta", pois acontece exatamente o contrário, ou seja, quanto menor o valor do coeficiente angular, mais próximo do eixo Ox a função estará.

\section{Fonte: da pesquisa}

A análise desta categoria possibilitou verificar novamente que os alunos não fizeram a relação do parâmetro $b$ em relação a função interceptar a origem do plano cartesiano. Também é possível afirmar que há alunos que se confundem ao registrar por meio da escrita a quantificação em relação a números negativos e por este motivo fazem a afirmação de que quanto maior o parâmetro $a$ mais próximo do eixo Oy a função estará. Acredita-se que o erro de registro em relação aos valores negativos do coeficiente angular seja um problema de registro, pois o software apresentou o comportamento gráfico da função na medida em que o valor do parâmetro era alterado.

No Quadro 4 apresenta-se a análise da terceira categoria que propõe a interpretação do comportamento da função quando da alteração do coeficiente angular e linear. Esta categoria, uma vez que a análise do coeficiente angular já foi realizada nas categorias anteriores, tem como objetivo demonstrar, especificamente, o comportamento da função ao se alterar o coeficiente linear.

\section{Quadro 4 - Análise da terceira categoria: $O$ valor do parâmetro a ser positivo ou negativo e o parâmetro $b$ diferente de zero}

\section{zero.}

Categoria: $\mathrm{O}$ valor do parâmetro $a$ ser positivo ou negativo e o parâmetro $b$ diferente de

Registro correto: Se $a$ for positivo a reta será crescente, sendo que quanto maior o valor de $a$ mais próximo do eixo Oy a reta estará e se o valor de $a$ for menor, mais próximo do eixo Ox a reta ficará. Se $a$ for negativo a resta será decrescente, sendo que quanto maior o valor de $a$ mais próximo do eixo Oy a reta estará e se o valor de $a$ for menor, mais próximo do eixo Ox a reta estará. Em relação ao parâmetro $b$, quando este é positivo ou negativo, a função intercepta o eixo Oy exatamente no valor determinado para ele.

\begin{tabular}{|c|c|c|}
\hline Dupla & Registro da dupla & Avaliação \\
\hline D1 & $\begin{array}{l}\text { A reta sempre interceptará o eixo de y no ponto } a \text { e } \\
\text { se deslocará pelo eixo de x conforme o ponto } b, \text { sua } \\
\text { classificação em crescente ou decrescente será de- } \\
\text { terminada pelo } a \text {, positivo ou negativo, se } b>0, \text { ela } \\
\text { se deslocará nos valores positivos em eixo y e nos }\end{array}$ & Crédito Parcial (CP) \\
\hline
\end{tabular}




\begin{tabular}{|c|c|c|}
\hline & $\begin{array}{l}\text { valores negativos no eixo de } \mathrm{x} \text {. Se } b<0 \text {, ela se deslo- } \\
\text { cará nos valores negativos do eixo y e positivos no } \\
\text { eixo de } \mathrm{x} \text { (se a }>0) \text {. A reta não passará pelo ponto de } \\
\text { origem do gráfico pois } b \neq 0 \text {. Se } b>0 \text {, a reta intercep- } \\
\text { tará valores positivos tanto no eixo y como no eixo } \\
\text { de } \mathrm{x} \text {. Se } b<0 \text {, a reta interceptará valores negativos } \\
\text { tanto no eixo de y quanto no eixo de x }(\text { se } a<0) \text {. }\end{array}$ & \\
\hline D2 & $\begin{array}{l}\text { Quando o valor de } a \text { for positivo e } b \text { também positi- } \\
\text { vo a reta assume valores positivos em y e negativos } \\
\text { em x. } \\
\text { Se } a \text { for negativo e } b \text { positivo os valores de x e y } \\
\text { serão positivos. } \\
\text { Se } a \text { for negativo e } b \text { negativo os valores de x serão } \\
\text { positivos e os de y serão negativos. }\end{array}$ & Nenhum Crédito (NC) \\
\hline D3 & $\begin{array}{l}\text { Neste caso, o coeficiente angular com valores posi- } \\
\text { tivos ou negativos, interceptará na condição da reta } \\
\text { ser crescente ou decrescente. } \\
\text { Alterando o coeficiente linear, ele desloca-se no } \\
\text { eixo de y (valores + = para cima; valores neg (-): } \\
\text { para baixo). }\end{array}$ & Crédito Parcial (CP) \\
\hline D4 & $\begin{array}{l}\text { A reta de } b \text { se desloca no eixo de x para valores po- } \\
\text { sitivos a esquerda e valores negativos se deslocam } \\
\text { para a direita. }\end{array}$ & Crédito Parcial (CP) \\
\hline \multicolumn{3}{|c|}{$\begin{array}{l}\text { D1: a dupla faz o registro correto do comportamento gráfico da função em relação a al- } \\
\text { teração dos parâmetros, porém coloca informações adicionais que dificultam o entendimento } \\
\text { daquilo que querem relatar e também cometem erro ao identificar qual o eixo do plano carte- } \\
\text { siano a função irá interceptar. }\end{array}$} \\
\hline \multicolumn{3}{|c|}{$\begin{array}{l}\text { D2: o registro efetuado pela segunda dupla tem a intenção de posicionar o quadrante } \\
\text { em que determinados pontos se encontram, porém, isso permite afirmar que se preocuparam } \\
\text { com pontos específicos da função e não na análise geral da situação solicitada. }\end{array}$} \\
\hline \multicolumn{3}{|c|}{$\begin{array}{l}\text { D3: no registro apresentado pela terceira dupla pode-se perceber que analisam correta- } \\
\text { mente o comportamento em relação ao coeficiente angular, mesmo usando o termo "intercep- } \\
\text { tará" de forma incorreta. Em relação a alteração do coeficiente linear os alunos percebem que } \\
\text { para valores positivos a função se deslocará para cima no eixo y, e para valores negativos a } \\
\text { reta se deslocará para baixo no eixo y. Entretanto, não apontam que o ponto onde a reta inter- } \\
\text { cepta o eixo de y é exatamente no valor determinado para o parâmetro } b \text {. }\end{array}$} \\
\hline $\begin{array}{l}\text { ciente } \\
\text { eixo }( \\
\text { ção ql }\end{array}$ & $\begin{array}{l}\text { 4: percebe-se que esta dupla analisa o comportamento } \\
\text { near, porém não se atenta para o que ocorre no eixo } \\
\text { Também não fazem nenhum comentário das alteraç } \\
\text { ido da alteração do coeficiente angular. }\end{array}$ & $\begin{array}{l}\text { da função em relação ao coefi- } \\
\text { Oy e assim ficam restritos ao } \\
\text { oyes do comportamento da fun- }\end{array}$ \\
\hline
\end{tabular}

Fonte: da pesquisa 
D3: Faz a afirmação correta em relação a reta constante, mas comete erro ao falar que a reta chegará perto do eixo Ox sem interceptá-lo e não registra a relação do valor do parâmetro $b$ com o ponto em que a função constante intercepta o eixo Oy. Pois, se o valor do parâmetro $b$ for igual a zero, a reta será um constante coincidente com o eixo Ox.

D4: Não cita que a função é constante, mas afirma que será paralela ao eixo Ox. E faz o registro que a reta se deslocará no eixo Oy dependendo do valor do parâmetro $b$ ser positivo ou negativo, mas não registra que a interceptação será exatamente no mesmo ponto que o valor de $b$.

Fonte: da pesquisa

Nesta categoria é possível identificar, pelo registro efetuado pelos alunos, que eles entendem que a função na forma incompleta $f(x)=b$ trata-se de uma função constante, ou ainda, uma reta paralela ao eixo Ox, porém não registram que o ponto de interseção entre a reta constante e o eixo Oy é exatamente no valor do parâmetro $b$.

Diante das análises realizadas, referente ao comportamento da função afim com base nos registros das quatro duplas, apresenta-se um metatexto sobre os registros realizados pelas duplas durante a atividade na intenção de apresentar quais as interpretações realizadas em função destes registros.

\subsection{O METATEXTO}

Aqui se relata a interpretação dos registros efetuados por cada dupla na tentativa verificar a aprendizagem do conceito de função afim por meio da utilização do software Geogebra, tendo em vista que estes alunos já tiveram contato com tal conceito.

A dupla D1 apresenta na atividade um bom aproveitamento do conceito de função afim, fazem os registros de acordo com o que visualizam no software, porém sempre na tentativa de complementar, ou ainda, melhorar a sua resposta, comentem erros nas informações adicionais. Acredita-se, tendo em vista a interpretação que a dupla realizou da atividade, que o erro na complementação da questão foi causado por uma desatenção no momento de registrar o nome dos eixos e até mesmo do ponto de interseção da reta e do eixo coordenado.

Já para a segunda dupla percebe-se que as informações apresentadas quanto ao conceito são parcialmente corretas por não descreverem as características da função de acordo com a situação analisada. Percebe-se que estes alunos não fizeram uma análise mais geral da situação estudada e em alguns momentos não perceberam os detalhes da função em relação a alteração dos parâmetros. Pode-se dizer esta dupla tem noção do conceito de função afim, porém não conseguiram entender quais as alterações causadas no comportamento gráfico da função quando da alteração dos seus parâmetros.

A penúltima dupla, assim como a anterior, apresenta registros parcialmente corretos, pois mostra em alguns momentos não ter conhecimento do conceito de função afim, mas em determinados momentos erram as informações. Tais erros podem ter sido cometidos por falta de atenção ou por desconhecimento de algumas particularidades da função afim e seus parâmetros. A dupla chega a relatar que o fato da função interceptar os eixos coordenados na 
origem do plano cartesiano ocorre por esta ter o coeficiente angular positivo, o que se pode dizer que é uma falta de domínio do conteúdo.

Da análise da última dupla pode-se dizer que fazem poucas observações a respeito do comportamento da função afim, não fazem menção quanto a classificação desta em relação ao coeficiente angular e nem quanto ao ponto de onde a reta intercepta o eixo Oy, apesar de comentar do comportamento da função constante em relação ao coeficiente linear. A dupla ainda comete um erro ao relatar o comportamento da função em relação ao coeficiente angular quanto este é negativo. Porém, o erro não é causado por desconhecerem o conceito de função afim, mas sim por não se atentarem a condição dos números negativos ao dizer qual número é maior que o outro.

Em resumo, apresenta-se abaixo, conforme Quadro 6, a avaliação realizada com base (categorias e unidades) nos registros feitos pelas duplas. Apenas uma das duplas não responde um dos momentos em relação ao comportamento da função afim, o que impossibilita afirmar que eles desconhecessem o conceito para que o registro correto fosse apresentado. No entanto, nenhum registro pôde ser considerado com crédito completo (CC), pois apresentavam informações incompletas.

Quadro 6 - Avaliação dos registros

\begin{tabular}{|c|c|c|c|c|c|c|c|c|c|c|c|c|}
\cline { 2 - 12 } \multicolumn{1}{c|}{} & \multicolumn{3}{|c|}{ Momento 1 } & \multicolumn{3}{c|}{ Momento 2 } & \multicolumn{3}{|c|}{ Momento 3 } & \multicolumn{3}{c|}{ Momento 4 } \\
\hline Duplas & & $\mathrm{CP}$ & $\mathrm{C}$ & $\mathrm{C}$ & $\mathrm{CP}$ & $\mathrm{NC}$ & & $\mathrm{CP}$ & $\mathrm{NC}$ & & $\mathrm{CP}$ & $\mathrm{NC}$ \\
\hline $\mathrm{D} 1$ & & $\mathrm{x}$ & & & $\mathrm{x}$ & - & & $\mathrm{x}$ & - & & $\mathrm{x}$ & - \\
\hline D2 & & $\mathrm{x}$ & & & $\mathrm{x}$ & - & & - & $\mathrm{x}$ & & $\mathrm{x}$ & - \\
\hline D3 & & $\mathrm{x}$ & & & $\mathrm{x}$ & - & & $\mathrm{x}$ & - & & $\mathrm{x}$ & - \\
\hline D4 & & $\mathrm{x}$ & & & $\mathrm{x}$ & - & & $\mathrm{x}$ & - & & $\mathrm{x}$ & - \\
\hline Total & & $100 \%$ & & & $100 \%$ & $0 \%$ & & $75 \%$ & $25 \%$ & & $100 \%$ & $0 \%$ \\
\hline
\end{tabular}

Fonte: da pesquisa

A análise dos registros da atividade permitiu compreender qual o conhecimento dos alunos em relação ao conceito de função afim além de indicar que possíveis erros são causados por desatenção dos alunos ou ainda por errarem conceitos matemáticos básicos que são considerados pré-requisitos. Tudo isso só foi permitido pela visualização dos gráficos criados no software Geogebra e pela possibilidade de simular graficamente, de modo 
dinâmico, as alterações em relação aos parâmetros da função afim. Além disso, assim como Borba e Villarreal (2005), acredita-se que

o conhecimento é produzido junto com uma dada mídia ou tecnologia da inteligência. Por esta razão, adotamos a perspectiva teórica que sustenta a noção que conhecimento é produzido por um coletivo composto de seres-humanos-com-mídias, ou seres-humanoscom-tecnologias, e não, como outras teorias sugerem, por apenas um ser humano individual, ou coletivo composto apenas de humanos (p. 23).

Assim, corrobora-se com Borba e Villarreal (2005) que o uso das tecnologias de informação e comunicação (TIC) contribui para a construção do conhecimento deixando de lado a noção ingênua de que estas são apenas auxiliares pedagógicos no processo de ensino e de aprendizagem.

\section{CONSIDERAÇÕES FINAIS}

O objetivo deste estudo é verificar a aprendizagem do conceito de função afim pelos alunos por meio da utilização do software de geometria dinâmica Geogebra. Nesse sentido, a criação de um contexto, a atividade mediada pelo uso da TIC, permitiu identificar falhas no processo de ensino e aprendizagem de Matemática, falta de atenção dos alunos na interpretação da visualização gráfica dentre outros. Porém, evidenciou-se que o uso desse instrumento tecnológico contribui para construção do conhecimento pelos alunos, pois estes podem adquirir conceito, modifica-lo, e ainda, aprimorar aquele previamente aprendido.

Toda essa constatação da aprendizagem só foi possível mediante a análise dos registros criados pelos alunos durante a realização da atividade. Apesar de os registros escritos permitirem algumas interpretações sobre os aspectos da função afim, baseados na análise de conteúdo, percebeu-se que o confronto de uma gravação dos diálogos dos alunos no desenvolvimento da atividade poderia contribuir para compreender alguns erros. No entanto, como não se efetuou a gravação, pode-se dizer que o registro escrito revelou certa falta de domínio do conceito de função afim e que as duplas cometeram equívocos na interpretação da visualização do gráfico gerado pelo software.

A atividade propiciou verificar o entendimento dos alunos sobre o conteúdo abordado na atividade bem como a percepção da necessidade de retomada do conceito de função afim com o auxílio do software Geogebra para que os alunos consigam interpretar a visualização gráfica proporcionada por esta TIC e assim modifiquem os conhecimentos anteriormente assimilados.

Todo esse processo possibilitou perceber uma falha no processo de ensino e de aprendizagem que mostrou a necessidade de retomar o conceito de função afim e de rever a prática docente de modo a pensar em diferentes formas de ensino de conceitos. Também se verificou que a aplicação de uma atividade na qual os alunos tem a possibilidade de manipular a TIC e registrar o que ele visualiza, fazendo conexões com conceitos prévios, permite a construção de conhecimentos além de permitir que estes tenham contato com outra forma de ensina e aprender. Este tipo de atividade poderá ser utilizado por estes acadêmicos no momento de ensinar a Matemática para seus alunos, já que se trata de um curso de licenciatura e entende-se como necessário o uso das TIC em sala de aula de modo a favorecer a construção do conhecimento pelos alunos e chamar a atenção destes para a aula mesmo com toda a presença da pós-modernidade na escola. 


\section{REFERÊNCIAS}

BURIASCO, R. L. C., Cyrino, M. C. C. T. \& Soares, M. T. C. Um estudo sobre a construção de um manual para correção das provas com questões abertas de matemática - AVA2002. In: Anais do VIII Encontro Nacional de Educação Matemática, Educação Matemática: um compromisso social, Recife, PE, Brasil, 2004.

BOGDAN, R..; BIKLEN, S. Investigações qualitativas em educação: uma introdução à teoria e aos métodos. Porto: Porto, 1994

BARDIN, L. (2009). Análise de conteúdo. 4. ed. Lisboa: Edições 70, 2009.

BORBA, M. C.; VILLAREAL, M. E.. Humans-with-media and the reorganization of mathematical thinking: information and communication technologies, modeling, experimentation and visualization. New York: Springer, 2005.

MOMO, M.; COSTA, M. V. Crianças escolares do século XXI: para se pensar uma infância pós-moderna. Cadernos de Pesquisa, v. 40, n. 141, p. 965-991, 2010. Disponível em: <http://www.scielo.br/pdf/cp/v40n141/v40n141a15.pdf>. Acesso em: 15 mar 2013.

MORAES, R.. Análise de conteúdo. Revista Educação. Porto Alegre, n.37, p.7-31, 1999.. Disponível em: <http://cliente.argo.com.br/ mgos/analise_de_conteudo_moraes.html>. Acesso em: 18 mai 2013.

STEINBRING, H.. The construction of new mathematical knowledge in classroom interaction: an epistemological perspective. Dordrecht: Springer, 2005.

VALENTE, J. A.. O computador na sociedade do conhecimento. In: VALENTE, J. A. (Org.). O computador na sociedade do conhecimento. Campinas: UNICAMP/NIED, 1999. 